\title{
The limits of practice: why realism can complement IR's practice turn
}

\author{
JONATHAN JOSEPH ${ }^{1}$ and MILJA KURKI ${ }^{2}$ \\ ${ }^{1}$ Department of Politics, University of Sheffield, Sheffield, UK \\ ${ }^{2}$ Department of International Politics, Aberystwyth University, Aberystwyth, UK
}

E-mail: j.joseph@sheffield.ac.uk

This paper argues that the current calls for a practice turn in International Relations (IR) while positive in many respects, are problematic and potentially limiting because they are premised on a confused understanding of the role of philosophy and realist philosophy in particular and a restricted view of the role of sociological investigation. This arises from the problematic tendency to lapse into advocacy of an anti-realist philosophical and sociological imagination. We suggest that the problems that practice theorists point to should lead not to knee-jerk anti-realism but rather can motivate a reinvigorated conversation with realism. This entails revisiting the role of philosophy, realism, and sociology in the study of practices. We argue that far from being antithetical to practice theory, a reconsideration of realist philosophy helps make sense of the role of practice and provides those advocating practice theory with better tools to deal with the challenges which motivated the development of these theoretical stances. Reconsidering realism entails, however, a reconsideration of a wider social ontology within which practice takes place, and openness to the role of philosophical and theoretical abstractions in teasing out the role of practice.

Keywords: practice theory; critical realism; scientific realism; Bourdieu; structure

In recent work there has been a growing momentum in favour of something called a practice turn in International Relations (IR). This turn consists of various strands of theorising, ranging widely from advocates of pragmatist analysis to followers of Bourdieu and exponents of Actor Network Theory (ANT) and assemblages. However, despite the differences of orientation which characterize these strands of practice theory there are also common themes that motivate them. Against constructivism's focus on 'inter-subjective' norms, and the obsessive concentration of many meta-theorists on 'abstract' theoretical questions of 'structure and agency', practice theorists seek to reorient how we understand international politics. They ask us to focus on analysis of an aspect of international politics which often goes 
unnoticed and unappreciated within existing theoretical perspectives. Theorists seeking a 'practice turn' ask us to focus on analysis of what they call 'practices', often unconscious and habitual, and 'background dispositions' acquired through practice (Pouliot 2008, 258).

As Vincent Pouliot powerfully argues, a practice turn is deemed necessary because practice theory is uniquely able to take on what he calls the 'representational bias' of IR theories, whether rational choice or constructivist. This bias arises from the attempts to explain 'from the outside', from an abstract, God-like 'IR theoretical' point of view, the patterns we 'see' in international politics, without first studying from the 'ground-up' how various agents of international politics, its diplomats, its social movement activists, its bureaucrats, actually understand their world and act in it. An approach attentive to practice is necessary as it brings to our attention the practices of world political actors and thus also reveals the implicit forms of 'background knowledge' embedded in their practices. In so doing the practice turn seeks to contribute to IR analysis moving away from 'armchair analysis' and closer to actualities of global political practice (Neumann cited in Pouliot 2008, 259).

Pouliot's (2007) methodological work specified what a more sociological move offers to IR: movement away from abstract theorizing in favour of attentiveness to practices in context. ANT theorists, while less willing to use the term 'sociology' (itself considered an abstraction which assumes a separate 'social realm') have also specified what a more association-attuned approach would entail in IR including methodological tools for keeping researchers attuned to analysis of associations as we find them (Bueger 2013). An implicit move to a sociological attitude is present here too, if only in the form of a critique of abstract IR theorizing.

The call for more sociological knowledge in IR has also been captured in work arguing for better understandings of IR scholars and their social context. Inanna Hamati-Ataya's work (2012a, 2012b, 2013) for example has provocatively called for a sociological turn in the analysis of knowledge construction in the IR discipline itself. This is because: 'If we adopt an abstract understanding of theory that treats the theorist as operating over and above the world that she studies, then we cannot produce genuine social science of the kind that influences the conduct and practice of world politics' (Hamati-Ataya 2013).

Similar interests have guided established approaches that reflect Wittgensteinian and pragmatist influences, particularly in their desire to situate everything within the realm of practices and practical knowledge. Recently reflecting on the strengths of the practice turn, Kratochwil argues that meaning is always constituted by links to other practices and not by any match between subject and object (Kratochwil 2011, 37). Indeed, he 
goes furthest of all practice theorists in claiming to reject philosophy itself on the grounds that it supposes a way that things really are (Kratochwil 2011, 45). While some forms of practice theory would appear to be sympathetic to philosophical argument, there is nevertheless a widespread scepticism towards conceptual abstraction beyond the realm of practices that is implicit in many of the arguments for the practice turn. We shall challenge such views from the perspective of critical realist philosophy.

In this piece we approach practice theory - in the first instance practice theory associated with Bourdieu - from the perspective of critical realism in order to draw out three issues that are in need of further, and more nuanced, consideration among those interested in developing and applying practice theory - philosophical argument and abstraction, conception of social structure, and understanding of sociology of practices.

Critical realism is located within the wider scientific or philosophical realist approach. We make a case here for philosophical and scientific realism but base our arguments, for clarity's sake, on the critical realist moves. ${ }^{1}$ This means that we accept Roy Bhaskar's particular understanding of the role of philosophy, first and foremost, as an underlabourer to the sciences. This seeks to clarify the method of investigation, analysing conceptual claims, rendering explicit those assumptions that are often implicit, drawing attention to the ontological claims that lie behind these and, most generally, producing knowledge of the necessary conditions for the production of knowledge and practice of science (Bhaskar 1989, 8). We suggest that an engagement with critical realism enables us to show why practice matters as well as how. It can also help to establish a wider and more open approach to the otherwise very welcome 'sociological turn' in IR. We choose the critical realist variant of realism here because of its greater emphasis on the possibility of understanding something like social structure as well as its more radical understanding of the relationship between structures, practices, and agents as a transformative and potentially emancipatory one. We also find merit in critical realism's emphasis on depth ontology and social stratification which we find particularly useful in critiquing some of the claims of practice theory. These arguments of critical realism need not, however, lead to a wholesale rejection of the arguments of practice theory. To clarify, we argue here that the study of practices can be profitably dealt with within a realist,

1 Terminological confusion is an ever-present difficulty in discussions of realist philosophy. In this article we make reference to philosophical realism, an umbrella term for various realist philosophies, scientific realism, Pouliot's and some others' favoured term for specific strands of philosophical realism which ground a philosophically realist position on science and 'critical realism', which is a particular sub-type of philosophical and scientific realisms. 
specifically critical realist, philosophical frame. We wish to argue that practice theorizing need not insist, negatively, on the rejection of philosophical realism and various associated ontological claims, but can, and historically already has, fruitfully accommodated assumptions which push in different directions.

We outline how critical realism can contribute positively to an understanding of practice and practice theory in three ways starting with a discussion of philosophy and the need for conceptual abstraction. If practice theorists rightly draw attention to the complex, messy, and overlapping nature of social processes, then there is all the more need for careful abstraction and conceptualization in order to identify the various components and influences and to consider how they combine and interact (Sayer 2000,19). We advocate a critical realist approach in order to show how this can be done.

Following this discussion the article moves to show how the problematic approach to abstraction leads to difficulties when it comes to the practice turn's mode of addressing the issue of how to theorise 'social structure'. In dealing with structure, we focus our discussion of structure in relation to Pierre Bourdieu's work in order to problematize the relationship between structure, agency, and practice. Although recognizing that Bourdieu's work is not representative of the practice turn as a whole, we focus on it here both because of its current popularity in IR, and because we believe it offers significant opportunities for a realist reading and reconstruction. Also, while the insights we develop in this section arise from and directly relate to practice theory engagements with Bourdieu, we also claim that the misreadings of Bourdieu may offer wider cautionary tales for consideration by other practice theorists who might wish to do away with attempts to theorise 'social structure'.

Finally, we identify how the failures to adequately address philosophy, realism, and abstraction in fact frustrate, rather than promote, a 'sociological turn'. We argue that critiques of realism lead to a very specific and, in our view, limited sociology of practices. With a particular focus on the arguments of Bourdieu, but driven by a belief that these arguments can also speak to engagements with approaches like ANT, we suggest that a realist corrective, based on a wider and deeper social ontology, is not only possible but desirable as an alternative avenue through which to address the very issues that practice theorists were concerned with in initiating their theoretical interventions.

Recognition of the positive contribution realism can make in debate on (limits of) practice theory is of importance in IR today because, as the practice turn has quickly become a leading new theoretical orientation to the study of International Relations, its consequences and implications for the study of IR are in danger of being misunderstood as a form of 
anti-realism and anti-(meta) theory. Practice theory is fast becoming the mainstream rival to constructivism, realism, and liberalism and attracting students from various theoretical traditions, including poststructuralism, constructivism, and postcolonialism and it is thus likely to continue to shape the discipline of IR in the next two decades. According to Kustermans (2016) it makes three promises - philosophically to overcome entrenched dualisms, theoretically to help account for change in world politics, and methodologically to account for politics as it actually occurs. How we approach, reflect upon, teach and utilize this research tradition then is of crucial significance. This article is an attempt to demonstrate that the practice turn needs to be both celebrated and its empirical insights welcomed, but also that it can be fruitfully critically interrogated and reframed. Through such reframing we may be able to more sharply observe both the limitations of this tradition and the potential that exists to extend it and augment it. At a minimum a conversation and a moment's reflection is, we hope, achieved through interpreting the insights of practice theory through a realist rather than an anti-realist lens.

\section{Practice theory, philosophy, and abstraction}

Practice theory is a broad term. There are disputes about what it is and what it says. We agree with recent interventions that suggest that we need to distinguish, for example, between a more Aristotelian focus on praxis or action and a more Wittgensteinian focus on social rules and framework (Frost and Lechner 2016); or between a pragmatic approach focused on action with fewer if any structural connotations, and a critical approach (usually drawing on Bourdieu) that embeds practice in power and hierarchies (Bueger and Gadinger 2015, 154-155). Recognizing this diversity, we do not wish to suggest that all practice theorists make similar arguments. Indeed, we go on to indicate some significant divergences on issues to do with philosophy, realism, and social structure. However, despite a lack of agreement on just what practices actually are and in what shared practice consists (Barnes 2001, 17), there are certain key orientations we can point to in practice theory.

In one of the major works on practice theory, Theodore Schatzki argues that practice theorists are united in their concern with the way that phenomena such as knowledge and meaning, science, power, language and social institutions are a part of the 'field of practices' and that the central core of practices are 'embodied, materially mediated arrays of human activity centrally organized around shared practical understanding' (Schatzki 2001, 2). In so doing, practice theory takes a materialist approach in seeing the social as a 'field of embodied, materially interwoven practices 
centrally organized around shared practical understandings' (Schatzki 2001, 3).

These arguments are echoed in recent work by Bueger and Gadinger that considers the practice turn in IR. Although noting the diversity of approaches being advocated, they identify core commonalities as: emphasis on process over stasis; development of an account of knowledge as action and the unity of doing and knowing; recognition of grasping knowledge as a collective process; advocacy of an approach that recognizes non-human elements as part of practices; rejection of a single reality in favour of a multiplicity of orders; and acceptance of a performative understanding of the world (Bueger and Gadinger 2014, 19-20, 2015, 453).

In IR practice theory has been developed from different angles: from the perspectives of Bourdieu and Latour as well as the 'classical' pragmatist perspectives. While each comes with differences of orientation, partially fleshed out below, central to all has been questioning reliance on abstract notions such as 'scientific method', 'inter-subjectivity', or 'agency and structure' in concrete explanations of international politics. This is partly because these terms problematically 'orient' our analyses of 'practice'. Instead of simply replicating the discipline's use of abstract terms and theoretical moves, practice theorists suggest that theorizing practice in the absence of actual practices makes little sense. The practice turn at its base calls for a more sociologically attuned focus on actual practices of international relations policy-makers, practitioners, and indeed scholars. As Kustermans notes, the focus is on the tangible and observable, the 'commonplace', the surface and the ontic level of reality 'where the common sense realist dwells' $(2016,191)$. Hence this focus is accompanied by a more sceptical attitude to abstract 'theory' as well as, relatedly, metaphysical philosophical claims which specify 'objects' abstractly, outside of consideration of practice. It is this sceptical attitude we wish to address here first, and the ways in which it can lead to a poor understanding of the role of philosophy, particularly as an underlabourer, and of realism as a philosophical approach to the social world.

A potent example of an abstraction-wary practice theorist in IR is Vincent Pouliot and our critique of practice theory in this section focuses mainly on his arguments. His scepticism of general IR theoretical and philosophical frameworks is reflected in his rejection of the 'epistemic' obsessions of Western thinkers. It is the tendency to abstract and 'look down from up high' on social developments that is problematic about epistemic practices: 'progressively the godlike posture of modern science, which looks at the world from above, triumphed over practical knowledge' (Pouliot 2008, 260). As the 'totalising representations' of maps do not 'convey the practical operations that made them possible', in the same 
sense IR theorists' frameworks centred on epistemological concerns about 'inter-subjectivity' or 'rational choice' blind us to the practical nature of the actual workings of international politics.

This is because abstractions lead to misreadings of what goes on in international politics, for 'one cannot impute to practitioners [of international politics] a theoretical perspective [as IR theorists tend to] that is made possible by looking at social action backwards and from above' (Pouliot 2008, 262). Theoretical and indeed philosophical categories and abstractions do not allow room for 'properly theorizing practical knowledge' (Pouliot 2008, 262). Thus, for example, abstractions such as agency and structure are to be rethought: 'Agency is not simply about "defying" structures by making choices independently of them. It is claimed to be a matter of instantiating structures, old and new, in and through practice. Without practice, intersubjective realities would falter; thus agency (or the enactment of practice) is what makes social reality possible in the first place' (Pouliot 2008, 264). Postmodernists as much as scientific realists are critiqued for not centring their analysis on practices but rather abstract notions of ontology, discourse, or language games (Pouliot 2008, 265).

For Pouliot, scientific realism is particularly prone to problematic tendencies to abstract, specifically through its insistence on the primacy of ontology and thus its insistence on the reality of objects of scientific study. Pouliot rejects as problematic (and dangerous) the idea of a 'world before knowledge' as it 'leads to reifying one's commonsensical and/or scientific representations as natural and universal' (Pouliot 2007, 363). He also rejects as hubris the insistence by realists that our models are depicting 'really real' realities. Science for Pouliot is not about 'defining big-R Reality' as his postfoundationalist constructivism seeks to 'problematize what is held to be real by looking into the constitutive effects of knowledge' (2007, 363). A turn to a sociological analysis of actors needs to be prioritized over predilictions of (meta)theorists.

The ANT approaches have a somewhat more complicated, yet not dissimilar orientation to sociology. The Latourian 'Actor-Network Theory' which has made notable inroads into IR (Best and Walters 2013; Bueger 2013, 2014, 2; Nexon and Pouliot 2013) draws on Latour's (2005, 2010) analysis of scientific practices. Instead of assuming 'we know' what actors are up to and that we can position, categorize and explain their actions and motivations on the basis of social scientists' abstract theories and concepts, Latour suggests we need to pay attention to the associations that actors or 'actants', social and natural, human and non-human, are networked in. He explicitly argues for a 'flat ontology' in the study of social life suggesting that this helps render the social world more clearly visible 
$(2005,16)$. This idea of visibility relates to an anti-abstraction position. Bueger and Gadinger (2014, 65) make this clear when they write that keeping ontology flat means reconceptualising the ideas that rely on construction of different levels and layers. This in IR means revisiting such things as system and unit, micro and macro, and local and global. Instead of working with philosophical or theoretical abstractions which create in our imaginations 'social structures', 'social relations', or indeed a realm of 'social reality', Latour argues we should simply focus on what we observe and describe: the networks and interactions of things in them. This is crucial because for him the critical edge of social sciences has been lost because of social theorists' almost ideological commitment to abstract categories of explanation which are imposed upon the 'objects' of analysis (Latour 2004, 2010). These abstractions 'reproduce' forms of life rather than enabling a critique of them.

Here there is a scepticism even of the glorification of 'sociology' as an answer - for Latour (2005), for example, it could be said that 'sociology' is part of the problem with its 'social theoretical' abstractions - yet similarly to practice theorists a closer study of actors in 'society' and 'the world', without philosophical foundations and abstractions, can help. Christian Bueger perhaps more than most has sought to show what the implications of an ANT-perspective are. He acknowledges that ANT 'shares many concerns with the pragmatist and practice theoretical ideas' and akin to them advises that 'researchers...seek proximity to the practices studied, to build theory from empirical insights and to rethink the character of representation' (Bueger 2013, 338). He points out the futility of starting research by assuming philosophical dualities as they 'come at a too high price and might prevent us from understanding what we want to know' (Bueger 2013, 339). He 'encourages us to build new conceptual apparatuses which do not rely on prior ontological commitments' (Bueger 2013, 340). Bueger's approach is consistent with the new interest in assemblage theory that draws on Latour and pragmatist philosophers as well as DeLanda and Deleuze and Guattari. In the first IR text to address this approach, Acuto and Curtis (2014) argue that it is possible to comprehend hybrids of different material, biological, social and technological components (assemblages) only by rejecting such reified general categories and abstract concepts like state, market, city, society, and capitalism. These are seen as reflecting 'modernist' thought rather than helping us to understand contemporary crises (Acuto and Curtis 2014, 2).

These critiques are interesting for at the heart of them lies an important critique of 'reifying' social theory which, instead of being puzzled by the world, too readily reaches for abstract philosophical solutions and concepts which then become moulds within which empirical observations are forced. 
We agree with this critique and thus the motivations for the turn to practice that informs the originators of practice theory, such as Bourdieu and Latour. Yet, we disagree with the view that in taking on these challenges it is a correct move to sidestep abstraction and philosophical underlabouring as if these simply reflect 'modernist thought'. Instead of lapsing into antirealism, philosophical realism, if examined properly, can be of assistance to practice theorists in responding to these challenges.

\section{Revisiting realist philosophy}

Strangely, despite the fact that in general the move towards practice sociology has been associated with (new) 'materialism' (rather than the more idealistic linguistic and discourse analysis approaches of poststructuralists and constructivists), the current IR practice turn arguments do not address realism in any detail and when they do, actively reject, as Pouliot's comments for example showed, what is perceived as 'philosophical' or 'scientific realism'.

By contrast, we start with the broader scientific realist position precisely because paradoxically it too starts with practice. Scientific realism, as a philosophy of science, argues that to understand the practices of scientists we need to understand their actions as being best explained as attempts to uncover the real mechanisms which underpin observable patterns (Bhaskar 1975). It argues that the intelligibility of science presupposes that the world is structured in a certain way and that despite being mind-independent, it is open to investigation. Critical realism (Bhaskar 1989) extends this realist understanding to the social sciences. It argues that the practice of social science is best understood as an effort to uncover social mechanisms, which are real even though they are not necessarily as 'stable' or consistent in their manifestations (due to the complexity of social interactions in 'open systems') as those observed in natural science laboratories. Bhaskar's critical realism critiques positivism and its vision of science head-on arguing that social science is not and cannot be seen as a search for observable regularities alone. But neither should we give up on causal analysis as postpositivist critics, aghast at positivist scientism, argue (Sayer 2000; Kurki 2008). Bhaskar argues we can build an epistemologically pluralist and ontologically realist middle way, which, while sensitive to 'interpretivism' and social construction, allows us to make judgements between accounts based on the belief that some of them are in principle more reality-congruent than others (although fixed criteria for discerning which are which are not readily available in social science).

Scientific and critical realist positions have been introduced into IR by various scholars such as Colin Wight (2006), Alex Wendt (1999), 
Heikki Patomaki (2002), Jonathan Joseph (2007), and Milja Kurki (2006, 2008). These scholars set out meta-theoretical positions which ground a critique of positivism in an analysis of scientific practice. They advocate postpositivism, but in a form that does not reduce social realities to language, norms, or beliefs of individuals. They argue for recognition of theorization and careful study of layered levels of reality making a distinction between the observed patterns and events and the unobservable causal structures. They argue importantly, for epistemological pluralism and methodological opportunism. In fact, contrary to poststructuralist or positivist philosophical perspectives, realism does not prescribe specific methods or epistemologies but leads us to accept that the questions we ask must direct the tools we use to answer these questions (Patomaki and Wight, 2001). On the one hand, therefore, critical realism assesses theories and methods based on their 'explanatory adequacy', on the other, it recognizes that explaining the real world requires a certain degree of abstraction and conceptualization in order to get at the underlying structures and mechanisms of this complex reality.

In this article we do not wish to rehearse the arguments revolving around philosophical, scientific, and critical realism in general or in IR as these have been extensively covered elsewhere (see e.g. Joseph and Wight 2010). What is of significance for us here is that realists argue for the need to theorise, that is conceptually abstract, in order to get at the unobservable causal mechanisms, forces and conditions which structure that which we empirically observe in social reality: the social world is not 'transparent' to us and in fact for the most part consists of unobservable forces which need to be conceptualized, often in abstraction, in order to be understood. Conceptualization is a necessary part of the scientific process that is required in order to trace signs of social norms, structures and beliefs in our empirical analyses.

The practice turn has so far shunned this approach because commitment to such realist philosophy would seem to entail 'abstraction' from the 'concrete practices' we are to base our analysis on, positing the existence of underlying, unobservable social relations, something that a flat ontology attempts to avoid or exclude. 'Philosophical' realism quickly becomes an anachronism for its (supposed) insistence on seemingly non-sociological grounds for philosophical claims about the underlying reality of natural and social kinds. Such prioritization of conceptual abstraction and ultimately a 'philosophical perspective' does not easily fit within the perspective which foregrounds sociological analysis of practice. These tendencies towards being sceptical of philosophical realism do not exist in isolation in IR. It could be argued that they are part of a wider move against philosophy in the discipline [see e.g. Monteiro and Ruby's (2009) critique 
of philosophical foundations, Sil and Katzenstein's (2010) analytical eclecticism or Lake's (2011) anti-ismic position].

Despite the prevalence of these sceptical tendencies in IR, we think it is important to consider further the wisdom of a position which reduces theorization or philosophy of knowledge itself to the 'sociological' focus on 'practice'. This is because the practice turn is weakened when it seeks to avoid reflection on philosophy and its relationship with sociology.

Indeed, we would like to suggest that the relationship between philosophy and sociology is far more nuanced than many practice theorists allow for and we get a sense of this if we reconsider the insights of the critical realist position on knowledge production and the role of philosophy. Below, we seek to make two points critical of the current practice turn: (1) We point out that misunderstandings of realism characterize the 'practice' of criticism of philosophy and realism; (2) We argue that if understood more accurately realism can, in fact, complement and add to practice theoretical attempts to develop a more 'sociological imagination' in IR.

First, it is important to point out that realist philosophy has been significantly misunderstood by its critics. Pouliot in particular misrepresents what realism is. Contrary to what he implies, scientific or critical realism does not seek to argue that we have direct access to the world around us or that our models are 'really real'. For critical realists, our knowledge is just as socially conditioned and structured as it is for the 'sociologically' inclined Pouliot, or indeed his inspiration, Bourdieu. However, where critical realists are closer to Bourdieu than they are to Pouliot is in their belief that, while we cannot have access to pure knowledge of society, because our accounts are 'of' something, not all of them are 'equal' to another and there are strong grounds for exercising what Bhaskar calls judgmental rationality - that is to say, in preferring one belief about something to another (Bhaskar 2009, 49). The philosophical move to ground practice of knowledge-production (or indeed the concrete practice of science for Bhaskar) on the assumption of ontological reality (to which we have no direct access) pre-existing 'our accounts' is a key move on which Bourdieu would arguably agree with realists rather than with Pouliot. Bourdieu's sociology, as we discuss below, was arguably grounded not just in 'practice' and 'sociology' but 'philosophical' acceptance of the reality of practices and constructions they give rise to. Pouliot's attempt to address scientific realism would benefit from a more detailed reading of realism and a re-reading of Bourdieu in the more philosophical, rather than merely 'sociological' vein.

ANT analysts similarly misjudge realism in adopting not just a philosophy-sceptical but a realism-sceptical position. Latour certainly is 
sceptical of 'philosophical' realism in that it entails for him a curious set of questions: why would we ask about whether 'reality' exists if we did not think that in fact our 'brains were in vats' with some sort of a 'reality' outside it (Latour 1999, 4)? Refusing the inside/outside dichotomy Latour is not interested in abstract debates on reality, hence his efforts to flatten ontology and how we approach the world. Yet, Latour is not necessarily an anti-realist; he certainly works with empirical realism. Further, we argue here that with an adequate understanding of philosophical realism in hand even Latour's approach is not entirely incompatible with philosophical realism for ironically philosophical realism is in fact an approach that is directly trying to address the concerns he holds so dear: why do we end up reproducing the beliefs of subjects in our social theories? We argue that philosophical realism can help clarify concerns of interest to practice theorists. It also points to some important problems and contradictions in practice theory as it is currently conceived.

One such clarification is recognition of the implicit role of philosophy in all social science. Realist philosophy's strength has arguably been to emphasize that even as social theorists think they are coming to the world 'pure' and 'un-weighed' by metaphysical systems, embedded in their thoughts, practices and knowledge are always, in fact, specific philosophical principles. The assumptions of 'naïve empiricism', and even of more sophisticated empiricisms (whether positivist or post-positivist), need to be critiqued for denying that the process of knowing is guided by ontological and epistemological assumptions. Whether it is empiricist insistence on the objectivity of empirical observation or pragmatist insistence on practical knowledge, all positions, according to critical realists, are premised on specific philosophical systems for connecting knowledge, knowers and the world (Bhaskar 1975). The benefits of a critical realist approach is that in acknowledging this and thus rendering these philosophical assumptions explicit, we can subject them to critical scrutiny.

This criticism is important to keep in mind when considering the arguments made by practice turn advocates in IR. From a realist perspective we can observe that in the practice theoretical accounts are indeed embedded specific philosophical principles (even if 'pragmatist' philosophical principles), which 'influence' their readings of 'sociology' and 'practice'. While keen to avoid a priori commitments, it may be that in so doing specific philosophical assumptions (whether on prioritization of practical knowledge, pluralist epistemology, or irrealist ontology) creep in. This is not all, for importantly realists point out that sometimes lack of reflection on ontology and epistemology results in theorists becoming inadvertently informed by problematic kinds of assumptions they have been seeking to avoid. 
One danger is that those positions that seek to avoid epistemological solutions often tend to 'lapse' into naive empiricism. While sceptical of the empiricism of positivist approaches, paradoxically, it could be argued that the prioritization of sociology without philosophical foundations also runs the risk of empiricist assumptions creeping back in. 'How do we know when we know?' is not a question that can be sociologically resolved because we are already 'in' knowledge structures; yet it is a problem that can be attenuated by being conscious of the ontological and epistemological assumptions we bring to our knowledge (of knowledge). The kinds of challenges Latour's 'critique of critique' poses for social theory then can be addressed, in a different way, through a realist critique of the consequences of his own 'solution'.

Realists also bring to our attention the problems inherent in embracing a flat ontology. This is to reduce the world 'that is' to 'events', 'practices', and thus the 'observable' and is characteristic of empiricism but also of many constructivist and postmodernist perspectives. This flat ontology leads to misunderstandings of causes and processes which do not exist at 'observable' levels of reality. As Bhaskar puts it: 'By secreting an ontology based on the category of experience, the domains of reality (the domains of the real, the actual, and the empirical) are collapsed into one. This prevents the crucial question of the conditions under which experience is, in fact, significant in science from being posed' (Bhaskar 1989, 15). Whether or not practice theorists perceive this as a positive thing, this flat ontology is a significant problem for their arguments. For example, it is difficult to make sense of things like habitus and background without some sense of ontological depth. When focused on practice a theorist can become uninterested in actually theorising 'abstractions' which would 'explain' practice and its conditions of possibility: as such they run the risk of reproducing the agents' conceptions and, worse, fail to explain the structural contexts of practices. Latour's challenge to social theorists is addressed again here, albeit differently, through a realist frame.

There is a deeper reason to be concerned - and one that practice turn theorists should be particularly concerned with. Philosophical foundations - explicit or implicit - have political and social origins and also implications. Latour (2004) in our view is right to argue that there may be problems that arise from the language of 'social science' for social scientists' ability to critique societal tendencies. In this way a critique of social theory or philosophy of social science is political. Equally, a realist critique of flat ontology of individualism, for example, is far from apolitical: in enables and grounds critiques which emphasize social relations and non-atomist (less liberal) imaginations. Much is politically at stake in being a realist, non-realist, or an anti-realist: yet, we are not sure these stakes are fully 
apparent, reflected on and dealt with in current debates. Certainly the limitations of realist philosophy can be reflected on but so can the consequences of standing against realism. Instead of hiding our philosophical or political commitments we here foreground an openly philosophically realist imagination of philosophy (and sociology) and one whose political openings and possibilities are openly available for discussion (see e.g. Kurki 2009). In our view, while practice theorists are entitled to adopt pragmatism (where knowledge is defined as what works), this should be openly defended, considered for its philosophical implications, and the consequences reflected on, politically. Friedrichs and Kratochwil argue that pragmatism is said to be best 'attuned' to the practice turn in social ontology with the added benefit that it rejects Marxist notions like false consciousness $(2009,713)$. However, as will become clear below, this is not the only interpretation of how to deal with practice and in fact sits uncomfortably with some of the founding figures of practice theorising. As we will see in the next section, Bourdieu's concern with how people are practically engaged in the field (and the false understanding they might have of this relationship) is at odds with pragmatist arguments that knowledge is simply a product of social activity.

\section{Drawing on Bourdieu's notion of social structure}

As we have shown, the practice turn is critical of abstractions as a way of approaching the study of the world. Indeed, the practice turn might seem to some to be an easy means to avoid problems of abstract debates in IR, for example the abstract debate on structure vs. agency. In this context importing Bourdieu into IR might be seen to be a way of adding a degree of sophistication to this debate given Bourdieu's own concern to overcome such a dualism. Bourdieu's, or Latour's, analytical frameworks might seem attractive in their opposition to the abstraction of concepts like structure and agency. Yet, to think we can avoid abstractions is a problematic way to come at theorising IR. Such approaches do not themselves escape abstractions - as we seek to show here through an analysis of IR treatments of Bourdieu's approach to 'social structure' - but also in denying abstractions they weaken their conceptualization of 'social forces'.

We will raise two issues here. First, we suggest that in its treatment of questions of philosophy and abstraction, the turn to Bourdieu in IR practice theory, has led to an instrumental appropriation of Bourdieu's work that interprets his arguments in either a shallow or selective way, specifically ignoring the significant role 'abstraction' played in his theorizing. Second, we argue that there are inadequacies in Bourdieu's own approach and suggest ways in which this can be better developed through adapting it to a 
realist social ontology. We focus here on the concept of structure because of its importance as an 'abstract' concept not only in the IR field and for critical realists but because of the problematic ways in which it has surfaced and continues to surface in practice turn analysis in IR. This is not to say that 'social structure' should necessarily be the main way to understand the social world from a realist perspective, but it is to say that such abstraction which gets at the ontology beyond practice is absolutely necessary. As we will show, at the heart of many of the problems with current practice theory is the inability to adequately abstract, and thus conceptualise, 'structure' (or whatever we would call underlying social context) due to a shallow or surface ontology and an inadequate understanding of the role of 'philosophical' arguments about social ontology.

Recent works by Vincent Pouliot (2007, 2008), Emanual Adler (Adler and Pouliot 2011), and Ted Hopf (2010) provide good examples of an inconsistent approach to Bourdieu and to the question of structure in particular. Most of the time this work maintains the kind of 'practice constructivist' ontology that places its emphasis on social practices and background knowledge. As we shall see below, there is occasionally a promising notion of structure that seems to be lurking in these ontologies. Yet such lurking conceptions of structure would seem to be inconsistent with the anti-realist stance present in much of this work and so is never properly elaborated into a coherent position. More common is a position that rejects the idea that structure has any meaningful existence in and of itself, and which conflates structure with its practical instantiation. This is what links these authors to the likes of Wittgenstein, Searle, Giddens, and other variations of constructivism. Other approaches like Rebecca Adler-Nissen's draw on Bourdieu, but seek to counter his 'tendency towards structuralism', in this case by using the symbolic interactionism of Goffman to place stress on role-playing, stigma management, and face-work (Adler-Nissen 2014, 18). Drawing on critical realism, we wish to show here why it is unnecessary to try to 'avoid' structuralism in such positions.

An initial definition of practice given by Adler and Pouliot in an influential recent article typifies the weak approach to structure and practice that we are criticizing here. Practices, they claim, are competent performances and socially meaningful patterns of action (Adler and Pouliot 2011, 4). This notion owes little to Bourdieu but, like Adler-Nissen's work, draws from Goffman: particularly, the emphasis on practice as socially meaningful and recognizable competence or performance (Adler and Pouliot 2011, 6). This is some distance from the Bourdieusian notion of practice. The idea of practice as resting on background knowledge is closer to Bourdieu but is not distinctively Bourdieusian and indeed the authors 
mention Wittgenstein at this point in their argument (Adler and Pouliot 2011, 7).

These initial suggestions lead us to express a degree of confusion when we find the notion of social structure emerging elsewhere in Adler and Pouliot's argument. Early on they mention the material and ideational processes that enable structures to stabilize or evolve and they talk, just like critical realists, of how agents may reproduce or transform structures (Adler and Pouliot 2011, 5). We later find a strongly appealing argument that 'practices stabilize social structures and fix ideas or subjectivities in people's minds' (Adler and Pouliot 2011, 20). This is appealing to us because it differentiates between practices and structures and conceives of practices as positioned in relation to structures as well as activities. The realist position, to clarify, argues that practices are socially meaningful activities, but that this meaningfulness depends upon their relation to the reproduction and transformation of underlying social structures and generative mechanisms.

Elsewhere, in discussing the practices of the international system, Adler and Pouliot mention the processes by which both social structures and social subjectivities are constituted by practices $(2011,22)$. This might be compared with the critical realism of Bob Jessop and Ngai-Ling Sum who, in outlining an approach they call cultural political economy, argue that practices are oriented to economic structures or systems, but that these are semiotically, organizationally and institutionally fixed as appropriate objects of intervention (Sum and Jessop 2013, 166). The problem in Adler and Pouliot's account, however, is that at no point is it made clear exactly what the notion of structure is referring to; it remains an unclear, unsystematic, and unreflexive notion. Our suspicion is that structure remains in their argument as a consequence of their use of Bourdieu and perhaps as a result of a difference of emphasis between the authors, but that it has very little actual meaning. Indeed, in their critique of abstract structures, a philosophical position on what structure 'means' is elided.

Although we may have some disagreement with his conception of structure, in contrast to the IR theorists, Bourdieu gives the notion of structure a more meaningful content, talking about such things as economic structures, kinship relations and linguistics. Elsewhere he gives further examples of what he means by structures, while emphasizing the need for a science of those structures that govern social practices:

the prerequisite for a science of common sense representations which seeks to be more than a complicitous description is a science of the structures which govern both practices and the concomitant representations, the latter being principal obstacle to the construction of such a science. Only by constructing the objective structures (price curves, chances of access to 
higher education, laws of the matrimonial market, etc.) is one able to pose the question of the mechanisms through which the relationship is established between the structures and practices or the representations which accompany them (Bourdieu 1977, 21).

This is clearly an account of the relation between structures and practices that requires us to make a significant ontological distinction. Moreover, Bourdieu's concepts of field and habitus can only be understood by keeping structures very much to the fore. To quote again from Bourdieu: 'These practices can be accounted for only by relating the objective structure defining the social conditions of the production of the habitus which engendered them to the conditions in which habitus is operating' $(1977,78)$.

Advocates of the practice turn might want to suggest that what this points to is not the kind of notion of social structure envisaged by critical realists, but simply the notion of field as background context. This could be given a deep hermeneutic basis as Hopf does in talking of the deep structure of our taken-for granted lifeworld (Hopf 2010, 554). This is a point worth discussing and it is not our aim here to claim that there is a consistently realist notion of social structure present across the vast range of Bourdieu's work. However, we do feel that it is easy to find, at the very least, a structural notion of field that would be consistent with a more realist approach and that this understanding is superior to the social ontology offered by the practice turn theorists, in which the meaning of the 'abstract' term remains empty and philosophically unexplored/unjustified.

At this point we should emphasize to the reader what is emerging as a central issue to us. Contrary to whatever the 'practice turn' is meant to imply for our research focus, in our view a key point of Bourdieu's own research programme is to highlight the limits of practice. This includes the limits of practical knowledge and consciousness.

Hence, we would argue that consistent with our views on realism, it is impossible to fully appreciate some of Bourdieu's key notions without recognizing the objective or real nature of social structures which is required in order to explain misrecognition, habitual reproduction and the largely unconscious nature of habitus. Bourdieu talks of practical taxonomies as 'a transformed, misrecognizable form of the real divisions of the social order... [that] contribute to the reproduction of that order by producing objectively orchestrated practices (Bourdieu 1977, 163). This makes the realist point that such practices produce misrecognition of a real situation. And rather than being a 'turn' to practice and agency, it reflects a central concern with their social or structural constraints, which in turn implies abstraction, which thus leads to the need to at least consider the 
attractions of a 'philosophically' realist, rather than 'flat realist/empiricist' reasoning on logic of explanation through practice.

Bourdieu's emphasis on limited understanding, unconscious reproduction, and misrecognition is consistent with the realist idea that social practices and habitus act as the means of mediation between structures and agents. It is through the unreflective practice or limited consciousness of agents in their routine activities that objective social structures are reproduced. Rather than rejecting the structure-agency relationship, this approach to practices highlights the nature of their relationship as well as suggesting that practices are 'positioned' or 'oriented' in a certain way. This is noted, for example, in Wight's treatment of Bourdieu where a habitus of positioned practices is a mediating link between agents and the socio-cultural world that they share (Wight 2006, 49). This in turn comes from Bhaskar's argument that we need to understand the 'point of contact' between human agency and social structures by examining a mediating system of positions - places, functions, rules, tasks, duties, etc., and practices, activities etc., which are engaged in by virtue of agents' occupancy of social positions. Crucially, this position-practice system is to be understood relationally (Bhaskar 1989, 40-41).

In our view there are significant arguments in Bourdieu's work that support the kind of relational approach favoured by approaches such as critical realism. Bourdieu argues that what exists in the social world are relations, not interactions between agents or intersubjective ties between individuals, but objective relations that exist, as Marx says, independent of consciousness. That is, whether you call social structure a social structure, there is something beyond the practices which orients actors and it is this relational orientation which social structure as an abstraction tries to 'get at' (whether it does so well, is another question). Crucially, the wider context is important: for Bourdieu it is provided by the notion of social field which is defined as a network of objective relations between positions (Bourdieu and Wacquant 1992, 97).

We pose this reading in strong contrast to that of Hamati-Ataya who claims that "ffield" and "habitus" signify Bourdieu's rejection of the concepts of "structure" and "agency". We also reject her Giddensian conflation of field and habitus where she writes, as a constructivist would, that 'field and habitus are mutually constitutive and therefore impossible to conceptualise or objectivate independently of each other' (Hamati-Ataya 2012a, 631). This represents the common problem of conflating problems of definition with the actual properties of the entities themselves. In actuality, it is clear from Bourdieu's work that field and habitus are seen as ontologically distinct, with different properties and causal effects. Hence Bourdieu argues that their relationship is a conditioned one. The field 
structures the habitus. The habitus is a product of the immanent necessity of a field. Habitus contributes to the constitution of the field as a meaningful world (Bourdieu and Wacquant 1992, 127). It seems odd to waste such a useful set of distinctions by using the somewhat ubiquitous constructivist description of 'mutual constitution'. Abstractions, whatever they are, should assist in explaining. Rather than being 'centrally conflated' (Archer 1995), within a realist frame the relationship between practices and their context can be seen through a process where antecedently existing relations constrain and enable agents who operate through a system of mediating positioned practices.

Such an approach, we believe, is, while not of course the final answer to theorising social practices, a more consistent and helpful approach in accounting for and delineating the context of practices. It relies on abstractions, but so do, in fact, practice theory accounts. We, and we think Bourdieu also, find these abstractions helpful in giving a sense of what practice does and how it does it without 'flattening' everything to practices to the point where nothing explains anything else and where practice starts to become an empty term. The problem with avoiding philosophical realism and abstraction is that it can drive practice theorists not only to a dismissal of reasonable realist claims about underlying causes and conditions of possibility, which would complement their vision, but also, as we argue in the next section, move them in the direction of a limited sociological vision.

\section{A limited conception of sociology}

We have argued here that the introduction of practice theory into IR tends to ignore some of the problematic philosophical basis of its theorizing and tends to shun or even misread realism. Certainly, there is a tendency to ignore the rather complicated equivocations on the question of realism and abstraction of Bourdieu [and Latour (2010, ch 1); and their differences on these questions (Bourdieu 2004, 28)]. As the latter part of this article has shown, closely reading and engaging with the realist tendencies in practice theory (we focused here on Bourdieu) reveals openings to philosophical realism. We argue here that practice turn scholars could benefit from open and perhaps even disputatious engagement with realism, abstraction, and philosophy. Ultimately, we think that this is necessary because the arguments against certain philosophical and realist arguments also lead to a problematic approach to sociology.

We have seen that the practice turn attempts to implement a sociological turn of sorts - but, it seems to us, it tends to advocate a limited sociology of actors and their experiences rather than a sociology that genuinely concerns 
itself with understanding the wider social field. Hostility to philosophical claims about the underlying nature of the social world means that, like positivism, practice theory informed by anti-realism is unable to conceptualize things beyond what is observable in practice and is thus trapped in an insider view of the 'field' that is remarkably unreflective about how the field itself might be constituted by anything other than the agents directly involved.

The consequences of this are particularly problematic to us from an IR perspective because it seems odd to talk about, for example, IR as a field without seeing that field as being heavily shaped by such things as its proximity to US structural hegemony or global capitalism. Critical realists like Andrew Collier (1989) would understand this in terms of 'two outsides', one being the intransitive world that theories seek to understand and the other 'outside' being the transitive practices of knowledge acquisition with their associated schools, institutions, networks, and practices. Practice theorists would of course talk about US hegemony and global capitalism but they would reduce these to their instantiation in the practices of the 'autonomous' field rather than seeing them as (at least partly) constitutive of the field itself. In an interesting argument Trine Villumsen Berling (2013) notes how the realist school in IR developed alongside NATO practices of balance of power and technical military integration. Although this is true, the explanation only goes so far.

By contrast, we see structural hegemony and global capitalism primarily in terms of social structure that orients practice rather than as social practice per se. This is clearly in opposition to practice theorists as well as constructivists who conflate the two as is evident in Pouliot's assertion of the ontological priority of the logic of practicality in relation to the mutually constitutive dynamics between agency and structure (Pouliot 2008, 259). It is also opposed to attempts to resolve the positioning of practice by recourse to other practices. Such is the case in Sending and Neumann's claim that there are certain 'anchoring practices' that render other practices possible $(2011,237)$. When they argue for a view of international organizations as a series of practices with some anchoring of others, we are entitled to ask, what anchors international organizations themselves? These issues go back to Ann Swidler's discussion of cultural practices where she suggests that anchoring practices constitute socially negotiated realities that coordinate basic social relationships. She talks of some 'structures' (like capitalism) as deeper and more fundamental and powerful than other practices, but then goes on to define these structures as 'constitutive rules' of which we have less direct knowledge (Swidler 2001, 81-86).

In contrast to these conflationist approaches, Bourdieu too offers an argument for a science 'of the dialectical relations between the objective 
structures to which the objectivist mode of knowledge gives access and the structured dispositions within which those structures are actualized and which tend to reproduce them' $(1977,3)$. We agree with this as an ontological statement (i.e. that there is an ontological distinction between objective structures and structured dispositions) but we disagree with the epistemological characterization of objectivism as a mode of knowledge. Indeed, we question the claim that the objectivist mode of knowledge does actually give access to objective structures. This is because Bourdieu conceives of objectivism as somewhat similar to what we would call positivism. Elsewhere Bourdieu talks of objectivism as something that establishes objective regularities. This is his understanding of such things as structures, laws, and systems of relationships that are independent of individual consciousness $(1990,26)$.

A lot depends on how we understand structures (and indeed perhaps this is not the most useful way to theorize 'context' of practices), but if there is a problem in Bourdieu's work it seems to us that it lies in the fact that he equates structures with the objectivist identification of them - an epistemic fallacy that equates real things with the knowledge we have of them. In fact we would advocate a more relational approach than Bourdieu insofar as he appears to identify objective structures with the positivist identification of empirical regularities whereas we maintain that structures are social relations or orientations. In short, we believe in objective social structures, or 'fields', beyond 'practices' while recognizing that these are relational in character. They are not reducible to regularities or patterns of behaviour or events. They have an existence independent of the agents who act within them. They have an underlying and often unobservable character. And they condition, and are revealed in, the more concrete practices that contemporary IR theorists seem so keen to foreground.

We thus follow William Carroll in bringing together realist arguments and Bourdieu's arguments about social fields. Realism addresses the problem of the disciplinary fields not by developing sociologies 'of the field' but by developing an integrated non-reductionist science of humanity as a whole. If there is a good reason for a 'sociological turn' it is not because 'sociology' will somehow help to explain what is going on in IR but because sociology is the best way to understand the world. And this, as Carroll ironically notes, is not because sociology represents a strong or coherent discipline but to the contrary, its virtue resides in its broad scope, porous boundaries and unsettled character all of which can help to undermine the 'enclosures' of disciplinary social science (Carroll 2013, 21). A broad, non-disciplinary, speculative and conceptually open and flexible sociology benefitting from realist philosophical insights is not antithetical to, although it develops in a distinct direction, the vision of 
Table 1. Approaches to Philosophy

\begin{tabular}{|c|c|c|}
\hline Practice view & Realist view & Combination \\
\hline $\begin{array}{l}\text { Philosophy linked to the } \\
\text { practice-knowledge- } \\
\text { action relationship }\end{array}$ & $\begin{array}{l}\text { Philosophy as both an } \\
\text { underlabourer and maker } \\
\text { of metaphysical claims }\end{array}$ & $\begin{array}{l}\text { Philosophy has a wide-ranging role } \\
\text { based on ontological realism, } \\
\text { epistemological relativism and } \\
\text { judgmental rationalism }\end{array}$ \\
\hline $\begin{array}{l}\text { Rejection of conceptual/ } \\
\text { philosophical } \\
\text { abstraction }\end{array}$ & $\begin{array}{l}\text { Need for conceptual } \\
\text { abstraction and } \\
\text { metaphysical arguments }\end{array}$ & $\begin{array}{l}\text { Practice theory gets at the empirics of } \\
\text { how practices work while realism } \\
\text { gets at underlying causal } \\
\text { mechanisms and conditions of } \\
\text { possibility }\end{array}$ \\
\hline Flat ontology & Stratified depth ontology & $\begin{array}{l}\text { Combination is not possible. Flat } \\
\text { ontology should be rejected in } \\
\text { favour of a stratified depth ontology } \\
\text { that includes practices as a central } \\
\text { part. }\end{array}$ \\
\hline Practice-based ontology & Structure-agency question & $\begin{array}{l}\text { Ontology of structure-practice-agent } \\
\text { with particular importance given to } \\
\text { the process of social reproduction as } \\
\text { well as unintended consequences }\end{array}$ \\
\hline $\begin{array}{l}\text { Wary of ontological } \\
\text { claims }\end{array}$ & $\begin{array}{l}\text { Ontological claims about } \\
\text { nature of reality }\end{array}$ & $\begin{array}{l}\text { Need ontological claims to situate } \\
\text { practices and our understanding } \\
\text { of them }\end{array}$ \\
\hline
\end{tabular}

social analysis of Bourdieu. It is this vision of sociology we wish to foreground.

This leads us to take stock of the contribution critical realism can make to practice theory. Rather than limiting philosophy to its relationship to practices, we argued that critical realism takes on board the need to make claims through abstractions about a wider and deeper reality. The above table clarifies the position we defend. In sum, we propose a philosophically realist form of practice theory which pays attention to the role of abstraction, the limits of flat ontology, the need to grapple with structures (unobservable as they are) and unintended consequences they can generate, and thus a wider view of sociology which is attuned not only practice but also the limits of practice (Table 1).

\section{Conclusion}

As Cornelia Navari (2011) notes, the notion of practice lies in the middle ground between more individualistic approaches and more holistic structural explanations. There is no reason to think that we have to choose between such options, but rather, the issue is where to place the emphasis. 
A critical realist approach helps insofar as it can see the distinctiveness of each aspect of the relationship between structure, practices, and agents. To put it in Navari's terms, social structures, although conceived of by us as underlying, are not to be understood separately from the agents' participation in them. Furthermore, we can agree with Janice Bially Mattern that: 'While structure is necessary for the emergence of practice, practice does what structure cannot; it generates human being' and that 'while practice creates agency, agency does what practice cannot: it transforms practice' $(2011,75)$. We agree with Bially Mattern that social structures cannot be understood separately from the agents' participation in them $(2011,618)$, a point also made by Bhaskar $(1989) .^{2}$ However, we also follow Navari's understanding of a more structuralist position as identified in Bourdieu's attempt to find 'an anchor in which to ground habitual behaviour' $(2011,263)$.

This article argues that there are limitations to the approaches to IR which prioritize practice. These limitations are partly philosophical and partly analytical but in their effects are quite concrete in shaping empirical accounts of world politics. If the practice turn leads to a failure to explain the conditions of practice, this turn may in fact obfuscate more than assist in IR theorists' attempts to grapple with complex world political processes. Practice theory is surely not without its uses: it can help to enlighten some new aspects of international politics and to explain some aspects of the activities of world political actors and indeed IR scholars. We also welcome the desire among a new wave of scholars to develop a critical approach that challenges the conservatism of established theories including both constructivism and poststructuralism. Also, the critiques of the potency of 'social science critiques' arising from approaches such as ANT are important. However, in turning to sociology through 'practice' there is a danger of IR theorists turning to sociology with a limited sociological imagination that restricts our ability not only to talk about the world, but also to critique and change it. We argue that realist foundations can provide an important grounding for practice theory. Realist philosophy cannot allow us to study the sociological trends and practices but can do this while maintaining a focus on the contexts that provide the conditions of possibility of practice. This leads to a richer and indeed potentially more questioning

${ }^{2}$ Critical realism argues that social structures, unlike natural structures, do not exist independently of the activities they govern. Nor are social structures independent of agent's conception of their activities. However, this intentional activity may have unconscious or unintentional consequences (of structural reproduction/elaboration). Social structures, in contrast to natural ones, are only relatively enduring. Their existence is 'spatio-temporally moored' and 'geohistorically reproduced, distantiated and transformed’ (Bhaskar 1989, 175). 
social science. Philosophical positions are not necessarily 'truths' - it would be presumptuous to assume the truth of any one philosophical system - but they do require engagement with because they are unavoidable in how we read the world and, moreover, give grounding to social analysis and political viewpoints. Similarly, abstractions such as 'social structures' are not necessarily the 'final words' that we should be forever bound to, yet they too are necessary and inescapable and when done well, can achieve exactly what critics like Latour call for, the kind of 'lifting' of our plane of sight from 'what and where we are'.

Rather than moving us away from concrete analysis, abstraction is precisely the means by which knowledge attempts to grasp the differentiations of the world and to individuate objects through characterising their main attributes and relations (Sayer 1992, 86). In particular, abstractions help us to identify structures, understood, according to Sayer, as sets of internally related objects or practices $(1992,92)$, and people, understood according to their positioning and roles within these structures and the possibilities and limitations that come with this. We believe that this is consistent with Bourdieu's approach and indeed with Michael Williams, one of the few IR scholars to have recognized the challenge posed by the necessity 'of abstraction, moving away from the purely subjective experiences of individuals to the structural level of the conditions of their possibility, without losing sight of the need to reintegrate these insights with the continual practical creativity of agents' (Williams 2013, 134).

While scientific and critical realism have been seen to be antithetical to the practice turn which has emphasized the need to 'flatten' ontological assumptions and avoid philosophical speculation, we have hoped to show practice theory need not be so. Practice theory, including Bourdieu's theorizing, can be understood and addressed through the realist tradition. We are not, to clarify, insisting on practice theory and realism as long-lost sister traditions naturally pushing in the same direction. Rather, we argue that interpreting the insights of practice theory through a realist lens, and thus also recovering the realist assumptions in practice theory of theorists such as Bourdieu, is fruitful for how IR theorists use and engage with this theoretical tradition. If practice theory is a tradition it is a wide-ranging tradition, which can be built, augmented and morphed into divergent directions. This realist orientation, we argue, is helpful today for IR theorists in both identifying what is at stake in theorizing practice in IR and in allowing a renegotiation of the nature of practice and practice theory in a way which allows for 'big theory', 'abstraction' and, crucially, also 'speculation' on causal forces beyond practice.

Just as pragmatism is not the only solution to our problems of knowledge, philosophical realism may not be the only solution either. Yet, in highlighting the limits of practice vision it can be a positive and 
productive way of understanding the significance and also theorizing the meaning of practices. Any commitments in a realist framework, or any other framework (such as pragmatism) should be reflexive and open-ended but, surely, as such, better than naïvely thinking we can face the world unhindered by philosophical or sociological problems of knowledge. Philosophy may not be the only solution but it is not a hindrance either; sociology may hold much promise but without a reflective philosophical grounding it too can result in an unhelpful reproduction of limited sociological consciousness.

\section{Acknowledgement}

The authors wish to thank the anonymous reviewers and William Carroll for their comments on previous drafts of this piece.

Jonathan Joseph is Professor of International Relations in the Department of Politics, University of Sheffield. His most recent books are The Social in the Global (2012) and Scientific Realism and International Relations (co-edited with Colin Wight 2010). He is currently finishing a manuscript on the idea of resilience and global governance and is an editor of Review of International Studies.

Milja Kurki is Professor at the Department of International Politics, Aberystwyth University. She is the author of Causation in International Relations (2008) and Democratic Futures (2013) and co-editor of various texts on IR theory and democracy support. She is currently interested in the nexus of social and natural sciences and reflection on the philosophical implications of cosmological science.

\section{References}

Acuto, Michele, and Simon Curtis. 2014. Reassembling International Theory: Assemblage Theory and International Relations. Basingstoke: Palgrave.

Adler, Emanuel, and Vincent Pouliot. 2011. "International Practices." International Theory $3(1): 1-36$.

Adler-Nissen, Rebecca. 2014. Opting Out of the European Union: Diplomacy, Sovereignty and European Integration. Cambridge: Cambridge University Press.

Archer, Margaret. 1995. Realist Social Theory: The Morphogenetic Approach. Cambridge: Cambridge University Press.

Barnes, Barry. 2001. "Practice as Collective Action." In The Practice Turn in Contemporary Theory, edited by Theodore R. Schatzki, Karin Knorr, and Eike von Savigny, 17-28. Abingdon: Routledge.

Best, Jacquiline, and William Walters. 2013. “'Actor-Network theory' and International Relationality: Lost (and Found) in Translation.” International Political Sociology 7(3):332-34. 
Bhaskar, Roy. 1975. Realist Theory of Science. Hemel Hempstead: Harvester Wheatsheaf. Bhaskar, Roy. 1989. The Possibility of Naturalism, 2nd ed. Hemel Hempstead: Harvester Wheatsheaf.

Bhaskar, Roy. 2009. Scientific Realism and Human Emancipation, 2nd ed. Abingdon: Routledge. Berling, Trine Villumsen. 2013. "Knowledges." In Bourdieu in International Relations, edited by Rebecca Adler-Nissen, 59-77. Abingdon: Routledge.

Bially Mattern, Janice. 2011. "A Practice Theory of Emotion for International Relations." In International Practices, edited by Emanuel Adler, and Vincent Pouliot, 63-86. Cambridge: Cambridge University Press.

Bourdieu, Pierre. 1977. Outline of a Theory of Practice. Cambridge: Cambridge University Press. Bourdieu, Pierre. 1990. The Logic of Practice. Stanford, CA: Stanford University Press.

Bourdieu, Pierre. 2004. Science of Science and Reflexivity. Cambridge: Polity.

Bourdieu, Pierre, and Loïc Wacquant. 1992. An Invitation to Reflexive Sociology. Cambridge: Polity.

Bueger, Christian. 2013. "Actor-Network Theory, Methodology, and International Organization.” International Political Sociology 7(3):338-42.

Bueger, Christian. 2014. "Pathways to Practice: Praxiography and International Politics." European Political Science Review 6(3):383-406.

Bueger, Christian, and Frank Gadinger. 2014. International Practice Theory: New Perspectives. Basingstoke: Palgrave.

Bueger, Christian, and Frank Gadinger. 2015. "The Play of International Practice.” International Studies Quarterly 59:449-60.

Carroll, William. 2013. "Discipline, Field, Nexus: Re-Visioning Sociology." Canadian Review of Sociology/Revue canadienne de sociologie 50(1):1-26.

Collier, Andrew. 1989. Scientific Realism and Socialist Thought. Hemel Hempstead: Harvester. Friedrichs, Jörg, and Friedrich Kratochwil. 2009. "On Acting and Knowing: How Pragmatism Can Advance International Relations Research and Methodology." International Organization 63(4):701-31.

Frost, Mervyn, and Silviya Lechner. 2016. "Two Conceptions of International Practice: Aristotelian Praxis or Wittgensteinian Language-Games?” Review of International Studies 42(2):334-50.

Hamati-Ataya, Inanna. 2012a. "IR Theory as International Practice/Agency: A Clinical-Cynical Bourdieusian Perspective.” Millennium 40:625-45.

Hamati-Ataya, Inanna. 2012b. "Beyond (Post)Positivism: The Missed Promises of Systemic Pragmatism.” International Studies Quarterly 56:291-305.

Hamati-Ataya, Inanna. 2013. "Defining Theory Down”, Blog Forum article, Duck of Minerva, Accessed November 28, 2013. http://www.whiteoliphaunt.com/duckofminerva/ 2013/09/defining-theory-down.html.

Hopf, Ted. 2010. “The Logic of Habit in International Relations." European Journal of International Relations 16:539-61.

Joseph, Jonathan. 2007. "Philosophy in International Relations: A Scientific Realist." Millennium: Journal of International Studies 35(2):345-59.

Joseph, Jonathan, and Colin Wight. eds. 2010. Scientific Realism and International Relations. Basingstoke: Palgrave.

Kratochwil. 2011. “Making Sense of 'International Practices'.” In International Practices, edited by Emanuel Adler, and Vincent Pouliot, 36-60. Cambridge: Cambridge University Press.

Kurki, Milja. 2006. "Causes of a Divided Discipline: Rethinking the Concept of Cause in International Relations Theory." Review of International Studies 32(2):189-216.

Kurki, Milja. 2008. Causation in International Relations. Cambridge: CUP.

Kurki, Milja. 2009. "The Politics of Philosophy of Science." International Theory 1(3):440-54. 
Kustermans, Jorg. 2016. "Parsing the Practice Turn: Practice, Practical Knowledge, Practices." Millennium: Journal of International Studies 44(2):175-96.

Lake, David. 2011. "Why 'isms' Are Evil: Theory, Epistemology, and Academic Sects as Impediments to Understanding and Progress." International Studies Quarterly 50(2):465-80.

Latour, Bruno. 1999. Pandora's Hope: Essays on the Reality of Science Studies. Cambridge, MA: Harvard University Press.

Latour, Bruno. 2004. "Why Has Critique Run Out of Steam? From Matters of Fact To Matters of Concern." Critical Inquiry 30(2):225-48.

Latour, Bruno. 2005. Reassembling the Social: Introduction to Actor-Network Theory. Oxford: OUP.

Latour, Bruno. 2010. The Modern Cult of the Factish Gods. Durham, NC: Duke University Press.

Monteiro, Nuno P., and Keven G. Ruby. 2009. "IR and the False Promise of Philosophical Foundations." International Theory 1(1):15-48.

Navari, Cornelia. 2011. "The Concept of Practice in the English School." European Journal of International Relations 17(4):611-30.

Nexon, Daniel, and Vincent Pouliot. 2013. “Things of Networks': Situating ANT in International Relations." International Political Sociology 7(3):342-45.

Patomaki, Heikki. 2002. After International Relations. London: Routledge.

Patomaki, Heikki, and Colin Wight. 2001. "After Post-Positivism: The Promises of Critical Realism.” ISQ 44(2):213-37.

Pouliot, Vincent. 2007. “'Sobjectivism': Toward a Constructivist Methodology.” International Studies Quarterly 51(2):359-84.

Pouliot, Vincent. 2008. "The Logic of Practicality: A Theory of Practice of Security Communities." International Organization 62(2):257-88.

Sayer, Andrew. 1992. Method in Social Science: A Realist Approach. London, New York: Routledge.

Sayer, Andrew. 2000. Realism and Social Science. London: Sage.

Schatzki, Theodore R. 2001. "Introduction: Practice Theory." In The Practice Turn in Contemporary Theory, edited by Theodore R. Schatzki, Karin Knorr, and Eike von Savigny, 1-14. Abingdon: Routledge.

Sending, Ole Jacob, and Iver B. Neumann. 2011. "Banking on Power: How Some Practices in an International Organization Anchor Others." In International Practices, edited by Emanuel Adler, and Vincent Pouliot, 231-54. Cambridge: Cambridge University Press.

Sil, Rudra, and Peter J. Katzenstein. 2010. Beyond Paradigms: Analytical Eclecticism in the Study of World Politics. Basingstoke: Palgrave.

Sum, Ngai-Ling, and Bob Jessop. 2013. Towards a Cultural Political Economy: Putting Culture in its Place in Political Economy. Cheltenham: Edward Elgar.

Swidler, Ann. 2001. “What Anchors Cultural Practices.” In The Practice Turn in Contemporary Theory, edited by Theodore R. Schatzki, Karin Knorr, and Eike von Savigny, 74-92. Abingdon: Routledge.

Wendt, Alexander. 1999. Social Theory of International Politics. Cambridge: CUP.

Wight, Colin. 2006. Agents, Structures and International Relations. Cambridge: Cambridge University Press.

Williams, Michael C. 2013. "Culture.” In Bourdieu in International Relations, edited by Rebecca Adler-Nissen, 131-47. Abingdon: Routledge. 